\title{
WIRELESS POWER TRANSMISSION TECHNOLOGY
}

\author{
Rahul Singh, Rajan Jain, Dheeraj Shrivastava \\ Department of Electronics and Communication Arya Institute of Engineering Technology, \\ Jaipur, Rajasthan,India
}

\begin{abstract}
Wireless power transmission (WPT) has covered a wide range of subjects in many fields and also become a highly active research area for student, scientist and many other because of their potential to providing new technology to our daily lives. The wireless power transmission will have bright future because this technology used in the transmission of electrical energy from a power source to an electrical load across an air gap without any wires. In this paper, we can study to present the existing technologies of wireless power transmission, their recent technology and future . Than we can also study of applications in wireless transmission.
\end{abstract}

\section{INTRODUCTION}

Electricity energy will be transport by the cord for the distribution of the energy. The major issue in this type of power transmission is the losses occurs when transmission and distribution process of electrical power due to the energy dissipation in the cord. The conductor and other equipment used for transmission in energy dissipation. In daily life the power generation and power loss are also increased. The cost of electricity is harmful to the environment due to the making of electricity. For reducing transmission loss is very crucial because the saved power can be used as an alternative to minimize the cost. Stored power loss during the transmission process is inevitable, some alternatives can be interpreted to soloved this problem. To minimize power losses in the power distribution network with using of wireless power transmission. That has been known for centuries to clean sources of electricity.

Battery charging with wireless power transfer is the best example of this. The concept of wireless power transfer is not a new idea for any thinks. It can be invented by researchers but not widely using in that time. WPT is new revolution in the mode of electricity transmission. That new revolution enable the reliable and efficient wireless charging of millions of everyday electronic devices with integrating a power source to an electrical load without any wires.

In the early time many different scientist proved different uses and thinks to transfer power without connection between the source and appliance. Every type of WPT has its own background histories, recent technologies and future scope.

To make this idea for familiarize for the new researchers we reviewed the The structure of this paper is : wireless power transfer

The recent technologies

applications of power transmission

conclusions

Acknowledgement

Section II

Section III

Section IV

Section V

Section VI

\section{WIRELESS POWER TRANSFER (WPT)}

Inductive power transfer also a name of wireless power transfer. It can be used for short range or even long range without cords. This WPT technology provides efficient, fast, and low maintenance cost as compared to other tecchnologies. It also allows portable electronics to charge themselves without ever being plugged in universal power wire. Power loss of this WPT technology is very less as compared to wired electricity transmission. The common function of WPT is to allow portable devices to be continuously charged and lose the constraint of a power cord. There are three main systems in WPT :

- Microwaves

- Resonance

- $\quad$ solar cells

Nikola Tesla was first which is conduct experiments dealing with WPT. His idea was that earth itself is a conductor that can carry a charge throughout the entire surface. When Tesla's experiments were not creating electricity, that time they just transferring it. This ideas can be applied to solve our energy crisis.

Small and portable technology is a part of everyday life. But from portability emerges another challenge is energy feild. Nowdays all portable devices are battery powered, they all must be recharged using the wired chargers. But using of WPT now instead of plugging in a cell phone, PDA, digital camera, voice recorder, mp3 player or laptop to recharge it, it could receive its power wirelessly. Although wireless power transfer is feasible and helps in human daily lives, but this technology suffers from several drawbacks namely requires a network of hundreds of satellites and interferences with other electronic devices.

There are two techniques in wireless power transfer:

A. near-field technique

B. far-field

\section{A. Near-field Techniques}

The near-field techniques are quantifying with appliance near from the potency source.

It have three categories:

1. electromagnetic radiation 
2. inductive coupling

3. magnetic resonant coupling

These techniques can be habituated to eliminate quandary due

to weather and security concerns.

1)Electromagnetic (EM) Radiation: Energy from the transmission antenna of a puissance source to the receiver antenna through radioactive EM waves is the process of emission by EM radiation. Omnidirectional radiation and unidirectional radiation, this two section relegated in the sense of the direction of emitting energy. Through omnidirectional radiation process, broadcasting EM waves via transmitter in an assigned ISM band for example $850-950 \mathrm{MHz}$ or $902-928 \mathrm{MHz}$ in the U.S. which can be varies with the different region both with $915 \mathrm{MHz}$ center frequency, and a receiver for example RFID tags tunes to the same frequency band to harvest radio puissance. In omnidirectional radiation though information transfer is more facile and congruous but withal suffers from a solemn efficiency quandary in energy transfer because when the distance is going sizably voluminous there is expeditious decay of EM waves. By the experiment it was found that when a receiver is $30 \mathrm{~cm}$ away from the RF transmitter, power transfer efficiency is only $1.5 \%$.

In additament, to forfend potential health hazards of humans from EM radiation, only felicitous process is omnidirectional radiation for ultra-low-power sensor nodes for example up to $10 \mathrm{~mW}$ with very low sensing activities like temperature, moisture and light. If there is a clear line-of-visual perception (LOS) path subsists in the process of unidirectional radiation, it can gain high power transmission over a much longer distance for example by utilizing a microwave or laser beam the range can be in kilometre. In the microwave-predicated system mostly, wireless power is transmitted on microwave frequencies of either 2.45 or $5.8 \mathrm{GHz}$, both in the ISM frequency band. In the Laser-predicated system, it is still considered less mature than microwave-predicated system, transmit power under the visible or near infrared frequency spectrum as an example from several $\mathrm{THz}$ to several hundred $\mathrm{THz}$.

2)Inductive Coupling: Inductive coupling generally defined as coupling between to LC circuits where resonant frequency is same. It works by utilizing magnetic field induction that is the natural part of current's kineticism through wire, as an example alternating current in a primary coil that is connected to a source can engender a varying magnetic field that induces a voltage across the terminals of a secondary coil at the receiver. Primary and secondary coils are two separate coils in inductive coupling. Every connected wirelessly and the reason of its simplicity, accomodation, and safety, inductive coupling has been a paramount and popular technology to transfer power without wires. With this technological application sundry kinds of electronic contrivances has been already made. Consequently, it has been prosperously commercialized to a number of products, including electric toothbrush, charging pad for cell phone or laptop, and medical implants. In inductive coupling, power transfer gradually decreases when the two coils are being separate gradually from each other or when the alignment of two coils is not impeccable. These kinds of quandaries are generally occurred when it's not meticulously utilized. It works best when the charging node of the contrivance and power receiving node are proximate in contact customarily less than a coil diameter, for example the range can be in centimetre and the direction of the charging must have to be aligned.

3)Magnetic Resonant Coupling: The last and most paramount category of WPT technology under the section of near field techniques is magnetic resonant coupling. This technology was developed by Kurs et al., which enable to make the interactions between two different objects very vigorously because of the coalescence of inductive coupling and resonance . In additament, energy will be shifting back and forth between magnetic field circumventing the coil and electric field around the capacitor. To the classical mechanical resonance the effect of magnetic resonance is analogous, under which a string when tuned to a certain tone it can be exhilarated to vibration by a faraway sound engenderer if there is a match between their resonance frequencies. In this technology, energy can be transferred efficiently from a source coil to a receiver coil with little loss of energy to alternating current in a primary coil (connected to a source) engenders a varying magnetic field that induces a voltage across the terminals of a secondary coil at the receiver. There are several advantages of this technology namely highly efficient, radiation loss will be negligible, provides much more preponderant range and directional as compared to inductive coupling.

\section{B. Far-field Techniques}

The far-field techniques are quantifying the electrical load far from the puissance source. These techniques aim at high power transfer and need line of visual perception. It can be disunited into two categories, which are microwave power transmission and laser power transmission .

1)Microwave Power Transmission (MPT): This technology transfers high power from the base station to the receiving station or mobile contrivances with two places being in line of optical discernment. With the avail of geosynchronous receiving and transmitting satellites, this technology enables the objects to acquire power from the base station with utilizing the magnetron. The first step of potency transmission is initiated with converting electrical energy to be microwaves energy and then microwaves energy will be captured with utilizing rectenna. Consequently, AC needs to be converted to Direct Current (DC) first and then DC is converted to microwaves by utilizing magnetron. Transmitted waves are received rectenna and then rectify microwaves into electricity with more efficiently. It will give DC as the output. 
2)Laser Power Transmission: This technology is marginally different with MPT where it enables the potency concentrated in a minute area by utilizing the mirror. This technology additionally engenders high powers that are coherent and not dispersed. In additament, this technology has been used to apply to a rover to explore the presence of frozen dihydrogen monoxide in the bottom of craters of the moon where no sunlight is available. On the other hand, the solar energy engendered by the radiation is converted into the electric energy. This energy next will be converted to the laser light and then transmitted to the rover working at the bottom of the crater.

\section{RECENT TECHNOLOGIES}

Utilization of resonance has rapidly grown in recent years to enhance the 3 efficiency of wireless energy transfer in a wide variety of applications. In additament, the indispensable core components of electronic product are being developed by electronic companies to avail speed the exordium of the technology into niche applications. This will boost our ingenious capacities to bring much more substantial transmutations in technology so that can be implemented in particular tasks. Some of these revolutionary applications have been launched into market, while others are not yare yet for the commercial market. For instance, automotive charging is a novel innovation but not available into market because of needing standardization in its charging infrastructure. On the contrary, a breakthrough innovation for traditional inductive charging in mobile electronic has already developed by a consortium company. To ascertain that multi-vendor products can charge anywhere in a mundane wireless ecosystem, the Standards Development Organizations (SDOs) is working to construct the interoperability standards in mobile contrivances for highly resonant wireless power transfer. All these efforts are paving the way toward incipient trend of wireless power technology, in which can be deployed in many applications.

\section{A. Qi Technology}

This technology utilizes the minuscule inductors to transmit power over higher frequencies and additionally support a charging distance of a few centimetres at most. As a result, portable contrivances have to be placed quite categorically on the dock for evading the shortage of an astronomically immense magnetic field. Owing to its circumscription on charging area, Qi components can utilize multiple resonator arrays to engender a more astronomically immense charging area. However, it still does not mitigate the quandary and even wasting an abundance of puissance to have individual coils switched on. In order to keep a vigorous enough connection, users consequently need to align their contrivances precisely with the magnetic fields.

Currently, the wireless charger can get warm during charging and it will heat up the back of a contrivance due to the operating frequency heating conductive materials. The Qi standard withal incorporates a inhibited communication protocol to circumscribe the potency consumed by multiple coils. With this, the receiving contrivance can tell the charger how much power it requires and when it is plenarily charged. Supplementally, the charger can modify its power output to suit any receiving contrivances and can switch to standby mode once the contrivance is plenarily charged or if no contrivance is affixed. Despite a wireless charger has not been as efficient as a customary charger, but Qi standard will able to be utilized in wireless charging in the near future.

\section{B. Coalition for Wireless Power (A4WP) Technology}

A4WP is a next-generation of wireless power transfer enabling the efficient transfer of puissance to electronic contrivances. This is predicated on reference power transmitting and receiving resonators without the utilization of interconnecting wires. This technology sanctions multiple contrivances to be charged with differing power requisites from a single transmitter at any one time. Because this technology utilizes a more sizably voluminous electromagnetic field rather than the minute inductor coils, ergo it enables contrivances to be charged without having to line-up precisely with the coil. Albeit A4WP has not relinquished to the market yet the subsistence of this technology enables the electronic contrivances to be charged in any positions including $\mathrm{Z}$ axis. A further advantage of A4WP is sanctioning charger to be embedded in the objects where the magnetic fields can still emit the energy from the objects.

\section{PMA Technology}

This is the organization with the aim of forward cerebrating in an ecumenical, not-for-profit, industry where better power paradigm for battery equipped contrivances utilizing wireless charging technology has been working with a bunch of research group bellwethers. Recently more than 100 members across a diverse set of industries including telecommunication, consumer contrivances, automotive, retail, furniture, surfaces and more are working with this incipient standard of technology. PMA magnification and prosperity is attributed to a unique approach of making wireless charging ubiquitous in the places that consumers need it most as well as the strenuous exertion and dedication for members.

TABLE 1. COMPARISON BETWEEN QI STANDARD, PMA, AND A4WP STANDARD

\begin{tabular}{|l|l|l|l|}
\hline \multirow{2}{*}{ No. } & \multicolumn{3}{|c|}{ Recent Technologies } \\
\cline { 2 - 4 } & \multicolumn{1}{|c|}{ Qi Standard } & \multicolumn{1}{|c|}{ PMA } & A4WP Standard \\
\hline 1. & $\begin{array}{l}\text { Magnetic } \\
\text { induction charging }\end{array}$ & Induction charging & $\begin{array}{l}\text { Magnetic } \\
\text { Resonance } \\
\text { Charging }\end{array}$ \\
\hline \multirow{2}{*}{2.} & $\begin{array}{l}\text { Lack of large } \\
\text { magnetic field }\end{array}$ & $\begin{array}{l}\text { Enough magnetic } \\
\text { Field }\end{array}$ & $\begin{array}{l}\text { Huge magnetic } \\
\text { Field }\end{array}$ \\
\hline
\end{tabular}


International Journal of Engineering Applied Sciences and Technology, 2020

Vol. 4, Issue 9, ISSN No. 2455-2143, Pages 444-449

Published Online January 2020 in IJEAST (http://www.ijeast.com)

\begin{tabular}{|l|l|l|l|}
\hline 3. & $\begin{array}{l}\text { Charging distance } \\
\text { a few centimetres } \\
\text { at most }\end{array}$ & Less than $10 \mathrm{~cm}$ & $\begin{array}{l}\text { Much larger } \\
\text { charging distance }\end{array}$ \\
\hline 4. & $\begin{array}{l}\text { Not easy to charge } \\
\text { more than one } \\
\text { devices at a time }\end{array}$ & $\begin{array}{l}\text { One device at a } \\
\text { Time }\end{array}$ & $\begin{array}{l}\text { Design allows } \\
\text { charging more } \\
\text { than one device } \\
\text { from a single } \\
\text { transmitter }\end{array}$ \\
\hline 5. & $\begin{array}{l}\text { Heat up the back } \\
\text { of the devices }\end{array}$ & $\begin{array}{l}\text { Heat up the } \\
\text { devices }\end{array}$ & $\begin{array}{l}\text { Don't heat up the } \\
\text { Devices }\end{array}$ \\
\hline 6. & $\begin{array}{l}\text { Uses small precise } \\
\text { inductor coil }\end{array}$ & Small coil & Much larger coil \\
\hline 8. & $\begin{array}{l}\text { Need to line up } \\
\text { perfectly within } \\
\text { the coil }\end{array}$ & $\begin{array}{l}\text { Line up with the } \\
\text { Coil }\end{array}$ & $\begin{array}{l}\text { No need to line } \\
\text { Up }\end{array}$ \\
\hline 100 products & $\begin{array}{l}\text { Member } \\
\text { Organization }\end{array}$ & $\begin{array}{l}\text { Very few } \\
\text { Company } \\
\text { Dorking for the } \\
\text { Development }\end{array}$ \\
\hline
\end{tabular}

\section{APPLICATION OF WIRELESS POWER} TRANSMISSION

In the field of wireless power transmission the distance between transmitter and receiver, which is going to be immensely colossal in the focus of recent research, can make the dream come true in different uses in human life. Applications depend on the utilizations of low power contrivances that can be wireless sensor or different electronic mobile contrivances, power range and highpowered contrivances in the field of industrial area, power range. Contrivances like led lights where supplying energy is directly connected with load can be defined direct wireless powering and different charging contrivances need to be battery or capacitor charge defined wireless charging could be two types of implemented system.

\section{A.Field of Electronics}

Electronics that is the most sizably voluminous application field of utilizing Wireless charging system is being implemented in electronic products such as laptop by utilizing a wireless power source deployed abaft the corkboard. This contrivance enables to distribute over 20 watts of potency. It can withal charge at a distance over a $40 \mathrm{~cm}$ from the wireless charging source.

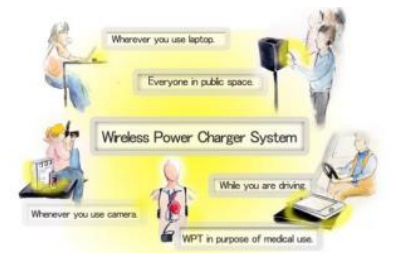

Fig. 1: Recent applications of wireless power charging system in our daily life.
Analysts expect that the benefits of charging over distance and with spatial liberation will result in highly resonant wireless power transfer capturing over $80 \%$ market quota of all wireless charging systems by 2020 . Mobile contrivances or astute phone that is capable to take charge from wireless charger is withal a great utilization of this technology. In the same way other contrivances like iPad or for camera charging in any time any moment even in the public places this wireless charging technology can be the greatest use for the human being.

\section{B. Medical Contrivances}

Wireless power transmission has been widely utilized for implanted medical contrivances including LVAD heart avail pumps, pacemakers, and infusion pumps. With utilizing this technology, the puissance can be efficiently supplied to medical contrivances deeply implanted within the human body. In integration, it can avail to eliminate the desideratum for drivelines that perforate the human body and for surgical supersession of primary batteries.

\section{Electric Conveyances}

Rechargeable hybrid and battery electric conveyances can be directly powered with wireless charging systems. These systems distribute $3.3 \mathrm{~kW}$ at high efficiency over a distance of $20 \mathrm{~cm}$. With utilizing this technology, it enables the reliable and efficient of puissance transmission to electric conveyances without the avail of wires. Moreover, it is expected that wireless charging will astronomically ameliorate the charging experience for EV owners, making such conveyances even more captivating to consumers.

\section{LED Lighting}

With utilizing wireless power transmission in LED (light emitting diode) lights, we can directly charge our contrivances utilizing wireless electricity so it can eliminate the desideratum for batteries in under-cabinet task lighting. Moreover, it can withal avail architectural lighting designers to engender products that ostensibly float in mid-air with no puissance cord.

\section{E. Bulwark Systems}

To ameliorate the reliability, ergonomics, and safety of electronic contrivances by wireless charging in the bulwark systems designers are engendering incipient design for the future bulwark technology. As an example Talon tele-operated robot is being equipped with wireless charging so that it can be recharged while it is being conveyed by truck from site to site. Another utilization of bulwark system is Helmet mounted electronics where night vision is included and radio contrivances that can be powered wirelessly from a battery pack carried in the soldier's vest, eliminating the desideratum for disposable batteries or a potency cord connecting the helmet to the 


\section{International Journal of Engineering Applied Sciences and Technology, 2020 Vol. 4, Issue 9, ISSN No. 2455-2143, Pages 444-449 \\ Published Online January 2020 in IJEAST (http://www.ijeast.com)}

vest mounted battery pack. Last few years a number of standards development organizations and industrial consortia have taken initial activities for the development of designations and standards relating to the application and commercialization of wireless puissance. The Society of Automotive Engineers (SAE) has a committee developing recommendations and ultimately a standard for wireless charging of electric and hybrid electric conveyances such as cars and buses. Moreover outside of North America, other international (International Electro technical Commission, or IEC) and national organizations (DKE German Commission for Electrical, Electronic and Information Technologies and the Japanese Automobile Research Institute, among others) are doing the same work for the development of more wireless charging applications. From the Consumer Electronics Sodality (CEA) is active in developing a standard for the deployment of wireless power technologies in consumer applications. Adscititiously, several industry consortia have been established for the development of designations about components and systems (as an example the recent three standards Wireless Power Consortium (WPC), Power Matters Coalition (PMA) and Coalition for Wireless Power (A4WP)). These kinds of efforts must be auxiliary for the most expeditious adoption of wireless power technology for the different wireless space application field.

\section{F. Solar Power Satellites (SPS)}

It is the most sizably voluminous application of WPT by utilizing satellites with giant solar arrays and placing them in Geosynchronous Earth Orbit. These satellites play a pivotal role to engender and transmit the puissance as microwaves to the earth. Another application of WPT is Ubiquitous Power Source or Wireless Power Source, Wireless sensors and RF Power Adaptive Rectifying Circuits (PARC).

\section{CONCLUSIONS}

The concept of wireless power transmission is presented. There recent technological applications that make the human life more benign in the present world have been discussed. Three incipient standard of wireless power technology that is already in competition with each other is adscititiously one of the verbalizes of the topic in near future when other more standards are coming anon. Among these three wirelesses charging standards, which are going to be win in the race that will be defined by their recent great applications. From the comparison table it shows that A4WP standards which has the immensely colossal magnetic field and immensely colossal charging distance must be keep ahead this technology then other standards whereas Qi and PMA withal ameliorating very expeditious. More applications that are in under research with wireless power charging and in the field of robotics will be in our quotidian uses only if wireless power keeps ameliorating.

\section{ACKNOWLEDGMENT}

The authors would relish to thank faculty and student members of Rajasthan technical University for providing equipment and material for this research.

\section{REFERENCES}

[1] Liguang Xie; Yi Shi; Hou, Y.T.; Lou, A., "Wireless power transfer and applications to sensor networks," Wireless Communications, IEEE , vol.20, no.4, pp.140,145, August 2013.

[2] Pawade, Sourabh, Tushar Nimje, and Dipti Diwase. "goodbye wires: approach to wireless power Transmission." Int. journal of emerging technology and advanced engineering. ISSN: 2250-2459.

[3] Teck Chuan Beh; Kato, M.; Imura, T.; Sehoon Oh; Hori, Y., "Automated Impedance Matching System for Robust Wireless Power Transfer via Magnetic Resonance Coupling," Industrial Electronics, IEEE Transactions on, vol.60, no.9, pp.3689,3698, Sept. 2013.

[4] Kurs, Andre; Moffatt, Robert; Soljacic, Marin, "Simultaneous mid-range power transfer to multiple devices," Applied Physics Letters , vol.96, no.4, pp.044102,044102-3, Jan 2013.

[5] Kurs, Andre, et al. "Wireless power transfer via strongly coupled magnetic resonances." science 317.5834 (2007): 83-86.

[6] Waffenschmidt, E., "Wireless power

$$
\text { for mobile devices," }
$$

Telecommunications Energy Conference (INTELEC), 2011 IEEE 33rd International, vol., no., pp.1,9, 9-13 Oct. 2011.

[7] Tianjia Sun; Xiang Xie; Guolin Li; Yingke Gu; Yangdong Deng; Zhihua Wang, "A Two-Hop Wireless Power Transfer System With an Efficiency-Enhanced Power Receiver for MotionFree Capsule Endoscopy Inspection,"Biomedical Engineering, IEEE Transactions on , vol.59, no.11, pp.3247,3254, Nov. 2012.

[8] Radiom, S., Baghaei-Nejad, M., Aghdam, K., Vandenbosch, G. A., Zheng, L. R., and Gielen, G. G. (2011). Far-Field On-Chip Antennas Monolithically Integrated in a Wireless-Powered 5.8-GHz Downlink/UWB Uplink RFID Tag in 0.18Standard CMOS. Solid-State Circuits, IEEE Journal of, 45(9), 1746-1758.

[9] Shouyin, Z. (2000, September). Development of quasi-optical microwave transmission lines in microwave diagnostics systems on Hefei tokamaks. InInfrared and Millimeter Waves, 2012. Conference Digest. 2000 25th International Conference on (pp. 89-90). IEEE.

[10]Feng, G., Wang, Q., Yang, P., Zhang, J., Wang, Z., and Liu, F. (2011, July). Diagnostic technology for temporal-spatial distribution of far-field high power laser beam profile. In Electronics and Optoelectronics (ICEOE), 2011 International Conference on (Vol. 2, pp. V2-30). IEEE.

[11] Ying Fu; Wang, T.; Johan Liu, "Microwavetransmission, heat and temperature properties of electrical conductive adhesive," Components and Packaging Technologies, IEEE Transactions on , vol.26, no.1, pp.193,198, March 2013

[12] Rajan Jian; Rahul Singh.; "Wireless power transmission technology;” Wireless 
International Journal of Engineering Applied Sciences and Technology, 2020 Vol. 4, Issue 9, ISSN No. 2455-2143, Pages 444-449

Published Online January 2020 in IJEAST (http://www.ijeast.com)

communications, Int. journal of emerging technology and advanced engineering. ISSN: 2455-

2143 DOI:10.33564, page 1-5, 2020 feb. 